\title{
The impact of extreme flooding events and anthropogenic stressors on the macrobenthic communities' dynamics
}

\author{
P.G. Cardoso ${ }^{\text {a,* }}$, D. Raffaelli ${ }^{\text {b }}$, A.I. Lilleb $\varnothing^{\text {a,c }}$, T. Verdelhos ${ }^{\text {a }}$, M.A. Pardal ${ }^{\text {a }}$ \\ ${ }^{a}$ IMAR - Institute of Marine Research, Department of Zoology, University of Coimbra, 3004-517 Coimbra, Portugal \\ ${ }^{\mathrm{b}}$ Environment Department, University of York, Heslington, York YO10 5DD, UK \\ ${ }^{\mathrm{c}}$ CESAM - Centro de Estudos do Ambiente e do Mar, University of Aveiro, 3810-193 Aveiro, Portugal
}

Received 8 February 2007; accepted 23 July 2007

Available online 15 August 2007

\begin{abstract}
Marine and coastal environments are among the most ecologically and socio-economically important habitats on Earth. However, climate change associated with a variety of anthropogenic stressors (e.g. eutrophication) may interact to produce combined impacts on biodiversity and ecosystem functioning, which in turn will have profound implications for marine ecosystems and the economic and social systems that depend upon them.

Over period 1980-2000, the environment of the Mondego estuary, Portugal, has deteriorated through eutrophication, manifested in the replacement of seagrasses by opportunistic macroalgae, degradation of water quality and increased turbidity, and the system has also experienced extreme flood events. A restoration plan was implemented in 1998 which aimed to reverse the eutrophication effects, especially to restore the original natural seagrass (Zostera noltii) community.

This paper explores the interactions between extreme weather events (e.g. intense floods) and anthropogenic stressors (e.g. eutrophication) on the dynamics of the macrobenthic assemblages and the socio-economic implications that follow. We found that during the previous decade, the intensification of extreme flooding events had significant effects on the structure and functioning of macrobenthic communities, specifically a decline in total biomass, a decline in species richness and a decline in suspension feeders. However, the earlier eutrophication process also strongly modified the macrobenthic community, seen as a decline in species richness, increase in detritivores and a decline in herbivores together with a significant increase in small deposit-feeding polychaetes.

After the implementation of the management plan, macrobenthic assemblages seemed to be recovering from eutrophication, but it is argued here that those earlier impacts reduced system stability and the resilience of the macrobenthic assemblages, so that its ability to cope with other stressors was compromised. Thus, heavy flooding in the Mondego region during the recovery process had more severe effects on these assemblages than expected, effectively re-setting the recovery clock, with significant socio-economic impacts (e.g. high mortality of fish in fish farms, and a large decline of economically important species, such as the bivalves Scrobicularia plana and Cerastoderma edule). The frequency and magnitude of these extreme events is predicted to increase in future years [IPCC WGI, 2001. Climate change 2001: the scientific basis, contribution of working group I to the third assessment report of the Intergovernmental Panel on Climate Change (IPCC). In: Houghton, J.T., Ding, Y., Griggs, D.J., Noguer, M., van der Linden, P.J., Xiaosu, D. (Eds.), Cambridge University Press, UK, 944 p.] and there is a risk that impacted ecosystems will never recover fully, with far-reaching consequences for human well being.
\end{abstract}

(C) 2007 Elsevier Ltd. All rights reserved.

Keywords: climate change; extreme flood events; eutrophication; multiple stressors; Zostera noltii; macrobenthos

\footnotetext{
* Corresponding author.

E-mail address: gcardoso@ci.uc.pt (P.G. Cardoso).
} 


\section{Introduction}

Among the most ecologically and socio-economically important environments on Earth are coastal zone ecosystems. Marine and coastal habitats have huge socioeconomic value, estimated at $\sim$ US\$ $15-20$ trillion $\mathrm{y}^{-1}$ globally, through food production, nutrient recycling, recreation and gas regulation (Hays et al., 2005; Harley et al., 2006). However, in addition to the numerous anthropogenic disturbances that affect coastal environments leading to habitat modification and changes in ecosystem function, these ecosystems, along with goods and services they provide are threatened by global climate change. Changes in climate (e.g. temperature rise, sealevel rise, increased risks of floods and droughts) may increase the risk of abrupt and non-linear changes in many ecosystems, which would affect their composition, function, biodiversity and productivity. When subjected to climate change, including changes in the frequency of extreme events, ecosystems may be disrupted as a consequence of differences in response times of species (IPCC WGI, 2001). Episodic events such as extreme rain events and flooding can result in the catastrophic deposition of fine sediments with profound influences on the structure and function of macrobenthic communities (Norkko et al., 2002).

In recent years there has been an upsurge of interest in climate change impacts in marine systems, but most of the literature is focused on the effect of the temperature and most work is conducted at the level of individual organisms (Harley et al., 2006 and references therein). A few studies have focused on the impact of large-scale weather events, such as flooding, on the functioning of macrobenthic communities (e.g. Norkko et al., 2002; Salen-Picard and Arlhac, 2002; Salen-Picard et al., 2003), confirming that extreme rain events may have implications for the ecosystem functioning. According to Norkko et al. (2002), catastrophic clay deposition associated with severe flooding, can have markedly deleterious effects on estuarine macrobenthic communities. Other studies have shown an increase in the density of opportunistic species after flood events (Salen-Picard and Arlhac, 2002; Salen-Picard et al., 2003).

Studies carried out on population- and community-level processes are required for a holistic and integrative view of the response of an ecosystem to global climate change, preferably over the long time scales associated with such change. However, there are relatively few long time-series of biological measurements in estuarine/marine environments (e.g. Beukema, 1991, 1992; Beukema et al., 1999).

In addition to climate change, coastal ecosystems such as estuaries are naturally subjected to a variety of anthropogenic stressors which can damage the health and fitness of the resident organisms. Multiple stressors including pollutants, excess of nutrients (e.g. eutrophication), altered habitat and hydrological regimes as well as floods and droughts can impact resources through single, cumulative or synergistic processes, lowering the overall system stability (Vinebrooke et al., 2004; Adams, 2005; Cardoso et al., 2005; Dolbeth et al., 2007). Responses of biota to these environmental stressors are the integrated result of both direct and indirect processes which can be manifested as changes in abundance, diversity and fitness of individuals, populations and communities (Adams, 2005). The accelerating rate of biological impoverishment may render ecosystems incapable of compensating for the loss of biodiversity, thereby reducing their resilience to environmental change (Vinebrooke et al., 2004). Distinguishing and integrating the effects of natural and anthropogenic stressors is an essential challenge for understanding and managing coastal biotic resources (Vinebrooke et al., 2004; Paerl, 2006).

This paper deals with the impact of multiple stressors (natural and anthropogenic) at the community-level processes in benthic ecosystems. In order to improve our understanding of benthic recovery processes following disturbance, the main goals of the present paper are to evaluate the impact of extreme events (e.g. intense flooding) on the dynamics of macrobenthic communities, using a long-term data series (10-years), and to assess possible interactions between climate change and other anthropogenic stressors (e.g. eutrophication).

\section{Materials and methods}

\subsection{Study site}

The Mondego estuary, located on the Atlantic coast of Portugal $\left(40^{\circ} 08 \mathrm{~N}, 8^{\circ} 50 \mathrm{~W}\right)$ consists of two distinct arms, northern and southern, separated by Murraceira Island (Fig. 1). A detailed description of the system can be found in Cardoso et al. (2004, 2005) and Verdelhos et al. (2005).

Mainland Portugal has a mild Mediterranean climate. Precipitation data for Portugal for the period 1931-2000 shows a generalized but weak decreasing trend that becomes more pronounced after 1976. Since 1976, there is also a significant difference in precipitation trends between seasons, with a systematic reduction of spring precipitation partially compensated by less coherent changes in the other seasons. Over all, the data imply a somewhat shorter rainy season. Climate data for the mainland reveals some increase in the frequency/intensity of extreme weather events in the second half of the 20th century. The maximum 5-day total precipitation, which is an indicator of flood producing events, is also increasing (Santos et al., 2002).

All data concerning monthly precipitation, presented in the present paper have been collected from the nearby city of Coimbra (Instituto de Meteorologia, Coimbra forecast station) since no meteorological forecast station was present in the study area.

In addition to climate change, the Mondego estuary has experienced marked eutrophication over the last 20 years, which led to a decline in the environmental quality of the estuary (including a replacement of seagrass beds by opportunistic macroalgae, increased degradation of water quality through increased turbidity and excess of nutrients, decline of species diversity and secondary production as well as a decline in herbivores and an increase in detritivores). This phenomenon has been reported fully elsewhere (Pardal et al., 2004; Cardoso 


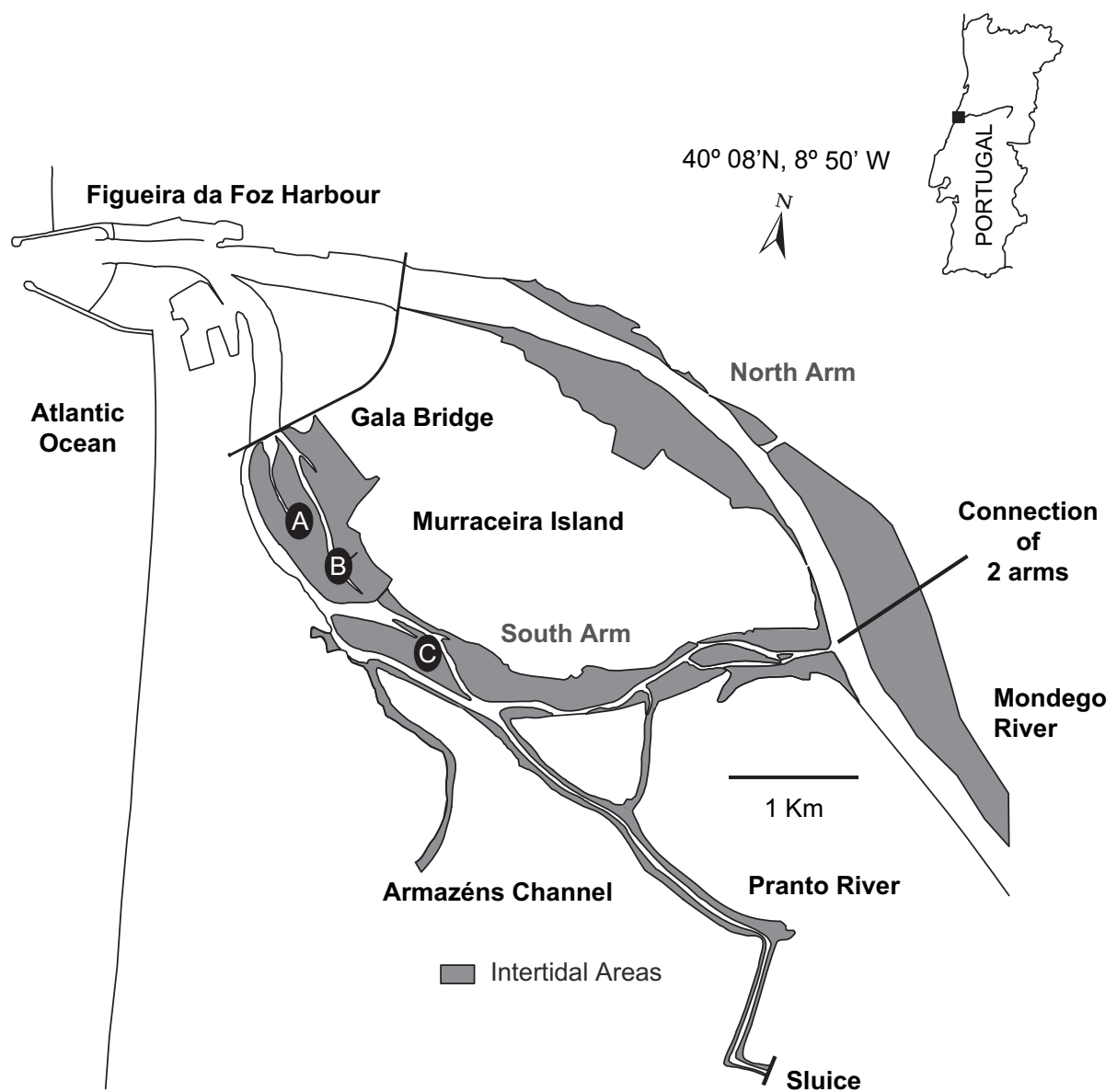

A - Zostera noltii bed
B - Intermediate area
C - Eutrophic area

Fig. 1. Location of the Mondego estuary and sampling stations.

et al., 2005, 2007; Verdelhos et al., 2005; Dolbeth et al., 2007). Due to the decline of seagrass beds and progressive impoverishment of the habitat, a management programme was implemented in 1998 in order to restore the original seagrass community. This programme included measures to decrease nutrient loading, physical protection of the seagrass bed and improvement of the hydraulic regime, by enlarging the connection between the two arms. The Pranto sluice-opening regime was changed so that most of the freshwater from the Pranto River was diverted to the northern arm, reducing the nutrient loading in the southern arm. In addition, the remaining seagrass patches were protected with wooden stakes to prevent further disturbance by fishermen digging in the sediment for bait and cockles (see in detail Cardoso et al., 2005, 2007; Lillebø et al., 2005; Verdelhos et al., 2005; Dolbeth et al., 2007).

Three distinct areas were selected as sampling sites along the southern arm: the seagrass Zostera noltii bed towards the marine end of the estuary, a eutrophic area further upstream and an intermediate area located in between (Fig. 1). In the 1980 s, the $Z$. noltii bed occupied a broad expanse along the southern arm (15 ha) reaching the inner most parts of the estuary (Cardoso et al., 2005). By the mid-1990s, Z. noltii had become restricted to a small patch $(0.02 \mathrm{ha})$ located downstream, having been replaced elsewhere by blooms of fastgrowing green macroalgae. The intermediate area located just upstream of the present $Z$. noltii bed has no seagrass cover, although some rhizomes remain in the sediment.

The eutrophic area located upstream comprises sandymuddy sediment, which in the early 1980s was covered by $Z$. noltii, but as eutrophication increased, Z. noltii declined progressively (Cardoso et al., 2005). This area has less energetic hydrodynamics than the others and is covered seasonally by green macroalgae (Ulva spp.) (Martins et al., 2001; Cardoso et al., 2002, 2004; Pardal et al., 2004).

\subsection{Field programme and laboratory procedures}

The macrobenthic assemblages were monitored from January 1993 to September 1995 and again from February 1999 to December 2002. Samples were collected fortnightly in the first 18 months and monthly during the rest of the study period. On each sampling occasion within each area, 6-10 cores $(13.5 \mathrm{~cm}$ diameter) were taken to a depth of $20 \mathrm{~cm}$. 
Samples were washed in estuarine water through a $500 \mu \mathrm{m}$ mesh and the fauna retained preserved in $4 \%$ buffered formalin. Later, animals were separated and transferred to $70 \%$ ethanol, identified to the lowest possible taxon and counted.

\subsection{Data analysis}

\subsubsection{Statistical analyses}

Changes in macrobenthic densities and biomasses were assessed using the non-parametric Wilcoxon two-sample test, comparing the pre- with post-restoration periods, for each study site.

Comparisons of species richness of the three study areas (before and after restoration) were made using a KruskalWallis test. For evenness, differences between pre-and postrestoration for the intermediate and eutrophic areas were assessed using $t$-tests.

The effect of flooding events on macrobenthos was statistically demonstrated through a non-parametric Wilcoxon twosample test, comparing the species richness before and after the floods of 2000/01.

Temporal changes in the structure of macrobenthic communities were assessed by multidimensional scaling (MDS) ordination on the Bray-Curtis similarity index and by Principal Response Curves (PRC) analysis (Van den Brink and Ter Braak, 1999).

\subsubsection{Macrobenthic trophic group assignments}

Each of the macrobenthic taxa was assigned to a trophic group based on feeding behaviour and food type. Trophic groups used in this study were detritivores (D), carnivores (C), herbivores $(\mathrm{H})$ and omnivores $(\mathrm{O})$. Since detritivores is the main trophic group, we decided to subdivide it into surfacedeposit feeders (SDF), subsurface-deposit feeders (SsDF) and suspension feeders $(\mathrm{SuF})$.

Some species could not be confidently classified using the available schemes and these were entered as "unknown". Preliminary analysis included the snail Hydrobia ulvae, but it was also decided to analyse trophic structure omitting this species, since it occasionally occurred in very high numbers and its inclusion masked changes in other species.

\subsubsection{Diversity measures}

The diversity of the macrobenthic assemblages in the three areas was assessed as species richness (simple count of number of species recognised), and by the Shannon-Wiener (log base 2), Simpson's D and Pielou's evenness measures (Krebs, 1999).

\subsubsection{Multivariate approaches: Principal Response Curves $(P R C)$ and Multi Dimensional Scaling (MDS)}

The spatial and temporal dynamics of macrobenthic assemblages along the eutrophication gradient were analysed by the Principal Response Curves (PRC) method. This method is based on the redundancy analysis ordination technique, the constrained form of Principal Component Analysis. A full account of the method can be found in Van den Brink and
Ter Braak (1999) and Pardal et al. (2004). The method computes differences in species composition between "treatments" (areas, in the present study) at each time point, similar to other ordination techniques. However, the advantage of this particular method is that any temporal changes in the "control" (the reference seagrass site in the present study), are constrained in the plot to a horizontal line, so that deviations from the control/undisturbed condition are more readily appreciated visually.

In the present study, "treatments" correspond to the different areas under different degrees of eutrophication. In previous studies that have used PRC analysis, an experimental "control" treatment level was used as the reference treatment (Van den Brink and Ter Braak, 1999). Here, however, and in common with Frampton et al. (2001) and Pardal et al. (2004), an obvious "control" treatment does not exist among sampling times, and the least disturbed (most natural) site is viewed as the control. Although a reference level must be specified in the PRC analysis, the choice of reference does not limit the visual and quantitative treatment contrasts that can be made using a PRC diagram (Ter Braak and Similaeur, 1998). We considered the Zostera noltii meadows in 1993 as the reference area or control. PRC analysis was performed using the CANOCO software package, version 4 (Ter Braak and Similaeur, 1998). The significance of the PRC diagram was tested using a Monte Carlo permutation, by permuting the whole time series in the partial RDA from which the PRC analysis is obtained, using an $F$-type test statistic based on the eigenvalue of the first canonical axis (Van den Brink and Ter Braak, 1999).

The faunal samples were also analysed using non-metric Multi Dimensional Scaling (MDS), described by Clarke and Gorley (2001) and Clarke and Warwick (2001). Numbers of individuals for each species were square root transformed prior to analysis in order to scale down the effects on the ordination of highly abundant species (Clarke and Warwick, 2001). To validate our interpretation of the MDS we performed the ANOSIM test (analysis of similarities), built on a simple non-parametric permutation procedure, and applied to the similarity matrix underlying the ordination of the samples (treatments) (Clarke and Warwick, 2001).

\section{Results}

\subsection{Climate-precipitation}

Our analysis of the seasonal accumulated precipitation pattern for Portugal for the last 60 years compared with the climate normal* of 1961-1990 (IM - Portuguese Weather Institute, http://web.meteo.pt), revealed many rainfall events exceeding $406 \mathrm{~mm}$ (mean winter precipitation for the period 1961-1990) (Fig. 2A). However, the frequency of flood events (precipitation in excess of $50 \%$ of the winter mean) has clearly increased during the last 30 years. Fig. 2B shows that from 1940 until the mid 1960's no flood events were recorded, while since then the frequency of flooding events has increased substantially. For instance, during the winter of 2000/01 precipitation 

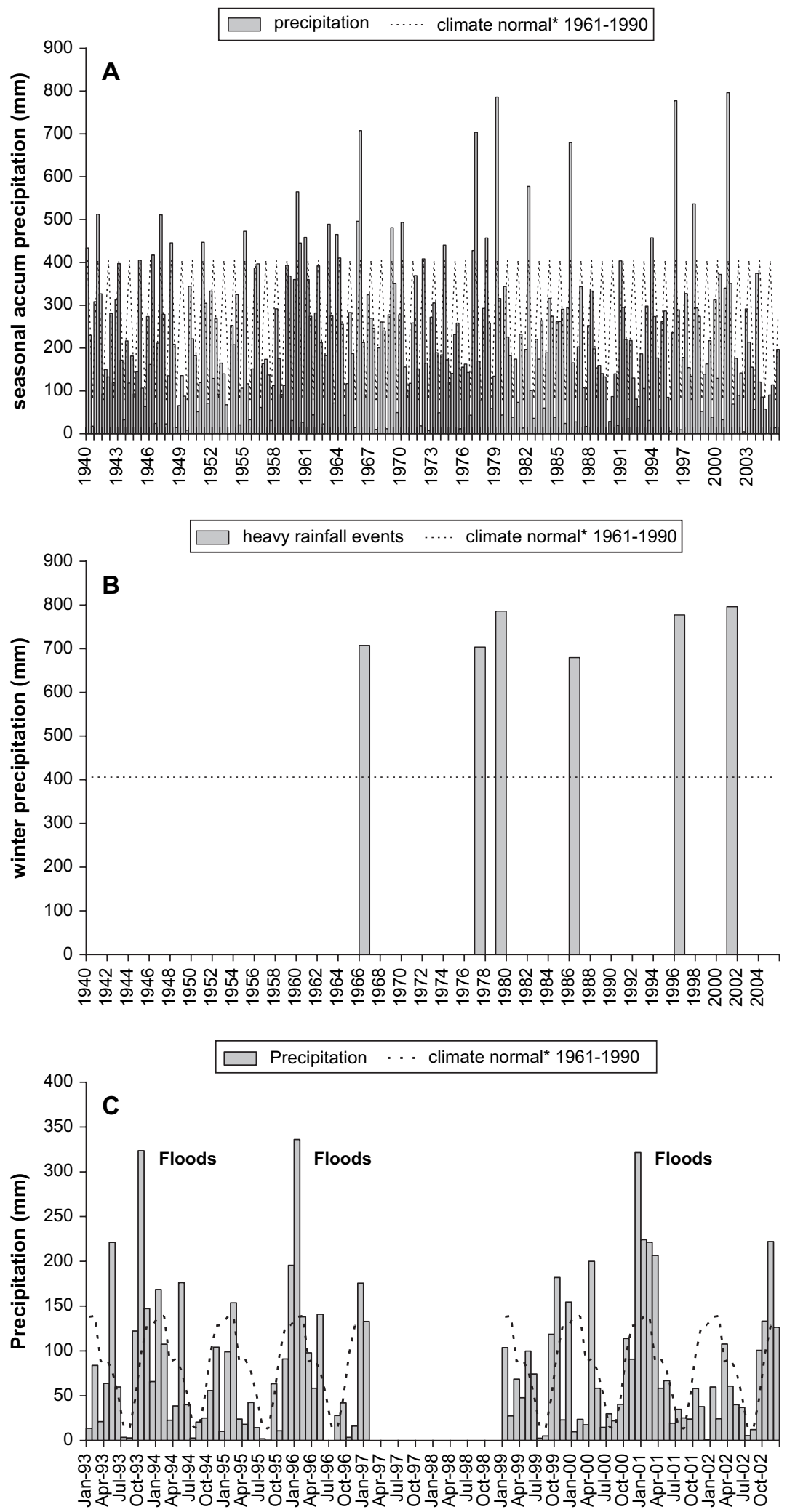

Fig. 2. Long-term variation in precipitation. (A) Seasonal accumulated precipitation for the centre of Portugal from 1940 to 2005. (B) Frequency of flood events (assuming values in excess of 50\% of the winter mean), for the centre of Portugal from 1940 to 2005. (C) Monthly precipitation compared to the climate normal* 1961-1990 for the centre of Portugal. *Climate normal of a climatic element is the mean value correspondent to a sufficient number of years to admit that it represents the predominant value of that element in a certain place. The World Meteorological Organization fixed that number in 30 years, starting in the first year of each decade (e.g. 1961-1990). The climate normal of 1961-1990 is considered a reference (IM - Portuguese Weather Institute, http://web.meteo.pt). 
reached unprecedented high values, especially for central Portugal (2000/01: 1802.1 mm against a mean annual value for 1961-1990 of $1016 \mathrm{~mm}$ ), causing a large flood (Fig. 2C).

The Mondego estuary is a warm temperate coastal system in a region with a typically Mediterranean temperate climate. It shows a clear seasonal pattern of precipitation throughout the 10 -year study period, with higher rainfall periods during winter. However, comparing the Mondego scenario with the mean precipitation regime for central Portugal for the period of 19611990 (winter: $406 \mathrm{~mm}$, spring: $257 \mathrm{~mm}$, summer: $79 \mathrm{~mm}$, autumn: $272 \mathrm{~mm}$; IM - Portuguese Weather Institute, http:// web.meteo.pt), three winters of above-average precipitation
(1993/1994, autumn: $593 \mathrm{~mm}, 1995 / 1996$, winter: $670 \mathrm{~mm}$ and 2000/2001, winter: $767 \mathrm{~mm}$ ) are apparent. In addition, 2000/01 was even more atypical than 1993/94 and 1995/96, since it was characterized by long periods of intense flooding (Fig. 2C).

\subsection{Macrobenthic assemblage dynamics}

\subsubsection{Changes in density and biomass}

In the Zostera noltii bed, during the pre-restoration period there was a general increase in macrobenthic biomass, whilst density showed annual cyclic oscillations (Fig. 3A).
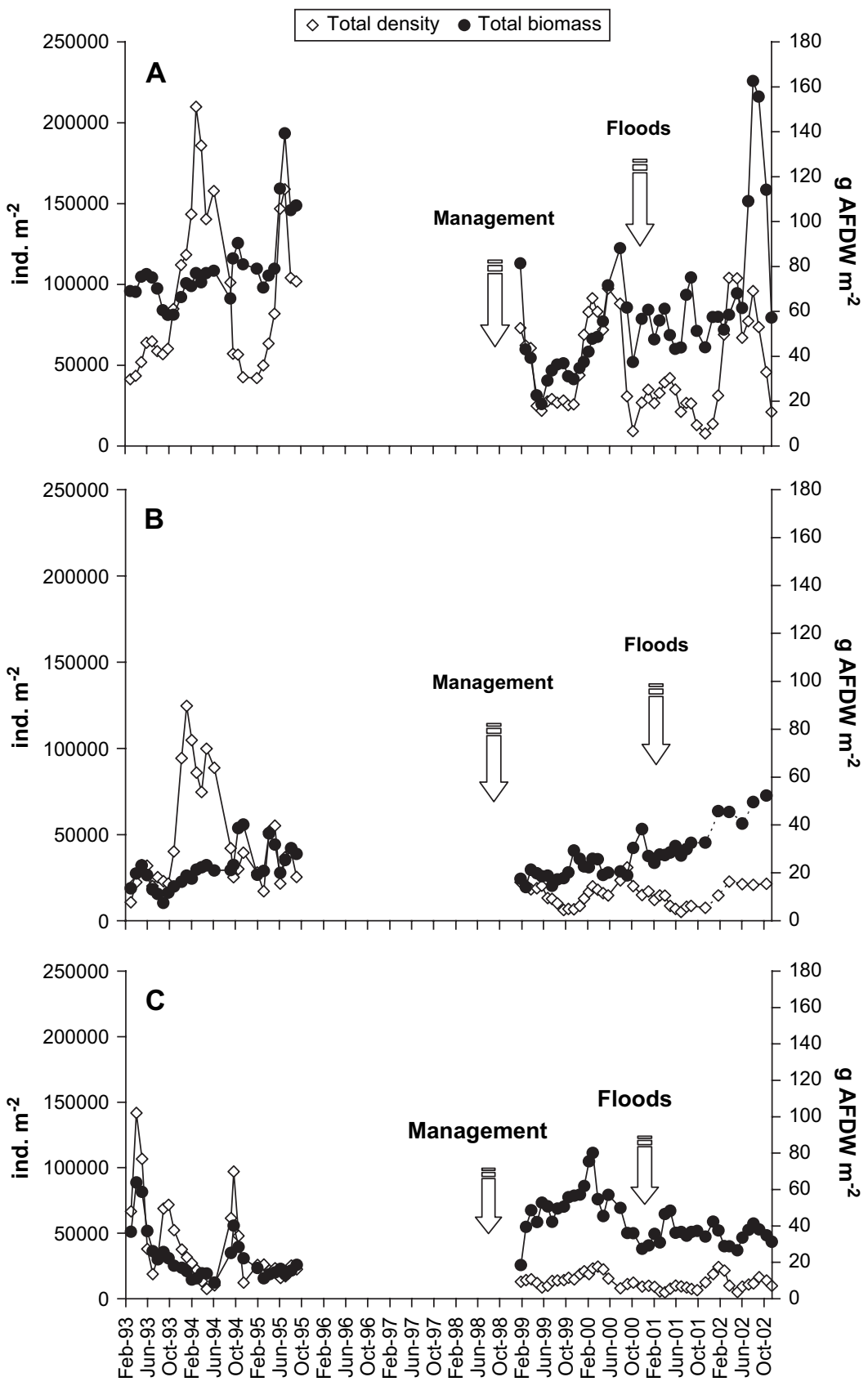

Fig. 3. Variation of density and biomass of the total macrobenthic community from 1993 to 2002. (A) Zostera noltii bed; (B) intermediate area; and (C) eutrophic area. 
Significant differences in density and biomass were recorded between the pre- and post-restoration periods (density, Wilcoxon two sample test, $W=1377, P<0.05$; biomass, Wilcoxon two sample test, $W=1438, P<0.05$ ). In contrast, in the eutrophic area, both density and biomass showed seasonal fluctuations over the pre-restoration period that could be related to algal blooms which occurred during that period (see Cardoso et al., 2005 for details) (Fig. 3C). Significant differences in density and biomass were observed between the pre- and post-restoration periods (density, Wilcoxon two sample test, $W=1491, P<0.05$; biomass, Wilcoxon two sample test, $W=558, P<0.05)$. The intermediate area displayed intermediate trends and patterns (Fig. 3B).

In the post-restoration period, recovery of biomass was greater and faster than the recovery of density (Fig. 3A-C).
However, this recovery phase was affected by the extreme precipitation event which occurred during the winter of 2000/ 2001. During this period a decline in total density and biomass of the macrobenthic community was apparent, just when it seemed to be recovering.

\subsubsection{Trophic groups}

Preliminary analyses which included Hydrobia ulvae were difficult to interpret, due to the masking effect of the large number of individuals of this species. Thus, the most representative groups were detritivores and herbivores, due to the dominance of $H$. ulvae, with other groups comprising only a small fraction of the community (Fig. 4A,I,III,V). Analysing in detail the detritivore assemblage, surface-deposit feeders (SDF) were the dominant group in all the three study areas. In
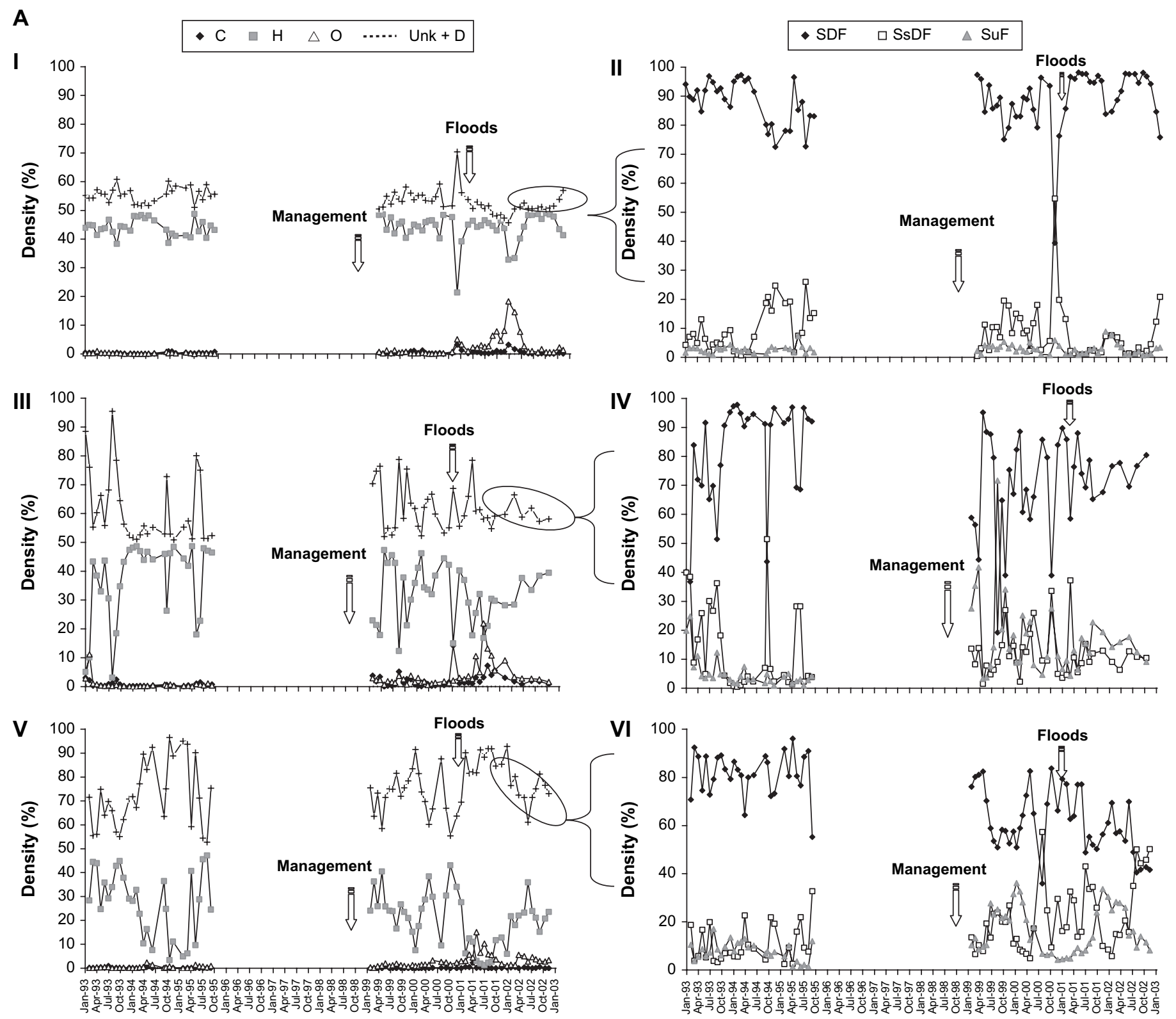

Fig. 4. Benthic assemblages of the Mondego estuary represented by trophic groups: surface deposit feeders (SDF), subsurface deposit feeders (SsDF), suspension feeders $(\mathrm{SuF})$, carnivores $(\mathrm{C})$, herbivores $(\mathrm{H})$ and omnivores $(\mathrm{O})$. Values are percentages of total individuals. (A) In the presence of Hydrobia ulvae; and (B) in the absence of Hydrobia ulvae, I, II - Zostera noltii bed; III, IV - Intermediate area; V, VI - eutrophic area. 

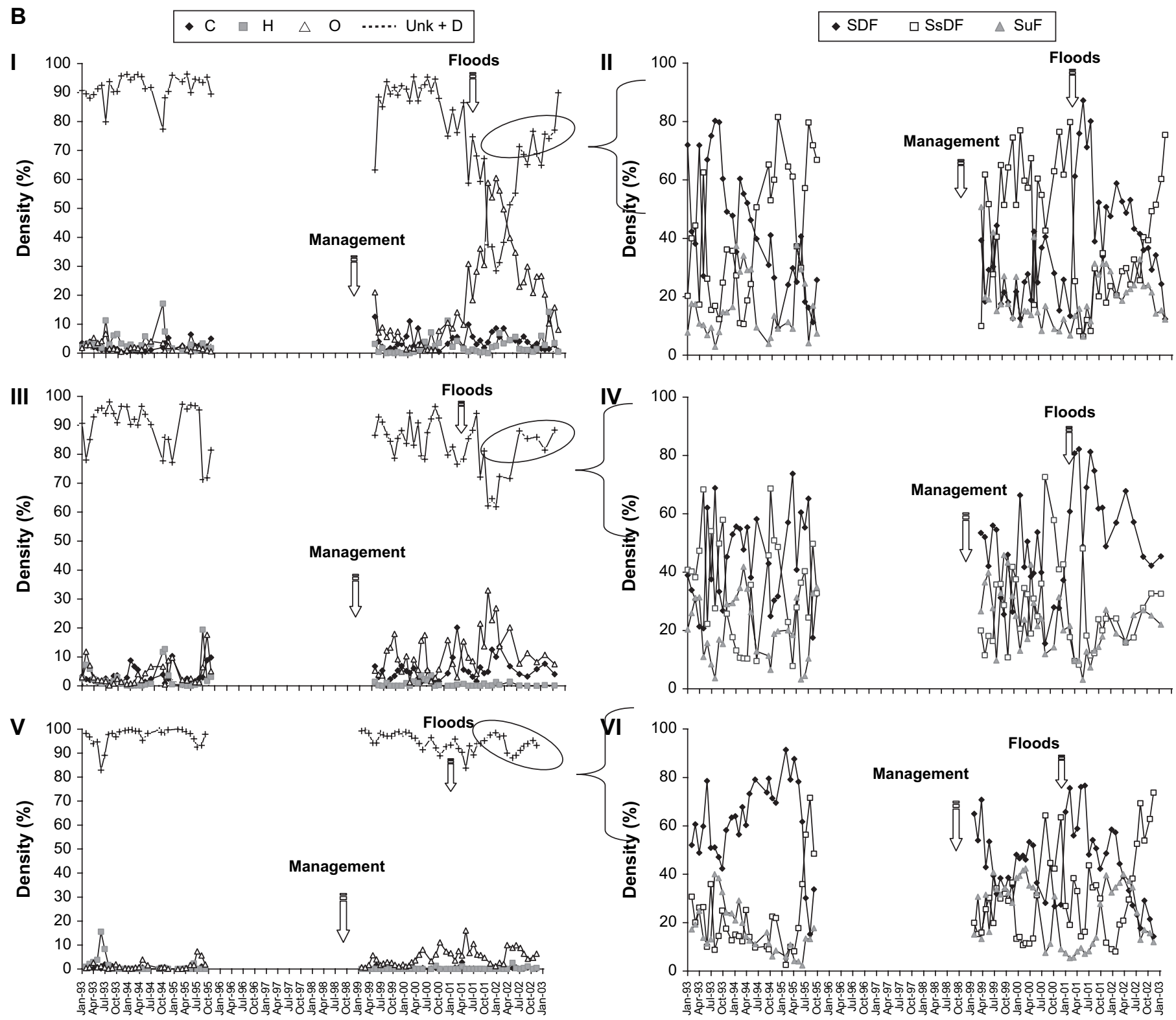

Fig. 4 (continued).

addition, in the Zostera noltii bed after the flood peak (December 2000) there was a large decline in subsurface-deposit feeders (SsDF) and an increase in surface-deposit feeders (SDF) (Fig. 4A,II). In the eutrophic area, there was a greater variability in the trophic structure from 1998 to 2002 compared to 1993 to 1995 period. This was particularly evident for suspension feeders (SuF), such as Scrobicularia plana, which were strongly affected by the large floods of 2000/01 (Fig. 4A, VI).

When Hydrobia ulvae are excluded from the analyses, macrofaunal communities continue to be dominated by detritivores, which together accounted for more than $90 \%$ of the total macrobenthic abundance (Fig. 4B,I,III,V). However, this analysis revealed a higher variability of the other trophic groups over time.

For the Zostera noltii bed during 2001, there was a marked decline in the percentage of detritivores, followed by a large increase in omnivores (e.g. Hediste diversicolor) (Fig. 4B,I). Within the detritivores, surface-deposit feeders declined from 1993 to 1999, following the decline of the seagrass Z. noltii and started to increase again in 2001/2002. In contrast, subsurface-deposit feeders (mainly small polychaetes) showed the opposite pattern, increasing from 1993 to 2000, declining abruptly after the floods of 2000/2001, and starting to recover in 2002 (Fig. 4B,II).

The eutrophic area had a different trophic structure compared to the seagrass bed. There was a gradual increase in subsurface-deposit feeders over the 10-year period and a decline in surface-deposit feeders, except for 2001 where there was a slight increase. In addition, suspension feeders increased in 1999/2000, but during the floods of 2000/2001, this group suffered a marked reduction, recovering over the following year (Fig. 4B,VI). 
The trophic structure of the intermediate area was much more erratic over time, but there was a clear increase in the percentage of omnivores, coincident with a decline in detritivores (Fig. 4B,III).

\subsubsection{Changes in diversity}

During the period 1993-2002 distinct changes in the structure of the macrobenthic communities were observed. More species were present from 1993 to 1995 compared to after the later period, and the seagrass bed generally supported more species than the intermediate and the eutrophic areas (Kruskal-Walli's test, $H=117.67, P<0.05$ ) (Fig. 5). Richness declined during the first three years of study for all the three stations (Fig. 5, Table 1). Following introduction of the restoration plan in 1998, species richness of the Zostera noltii bed and of the intermediate area started to increase and became more similar until the winter of $2000 / 01$. At the end of 2000/01 there was an unprecedented high rainfall in December and January that caused the largest Portuguese flood of the twentieth century, consistent with observations by the Portuguese Weather Institute (IM - http://web.meteo.pt/pt/clima/ clima.jsp) that climate in the region has become more extreme in recent times compared to period 1961-1990. Significant differences in species richness were recorded between the pre- and post- 2000/01 floods (Seagrass area, Wilcoxon two sample test, $W=2427.5, P<0.05$; Intermediate area, Wilcoxon two sample test, $W=2017.5, P<0.05$; Eutrophic area, Wilcoxon two sample test, $W=2197, P<0.05$ ). After this extreme event, species richness only started to recover again in 2002 (Fig. 5A, Table 1).

Evenness was lower in the Zostera noltii bed due to the dominance of Hydrobia ulvae at this site, and higher in the intermediate and eutrophic areas (Fig. 5B). Evenness increased over the 10 -year period for the intermediate and eutrophic areas, showing significant differences between the pre- and post-restoration periods (Intermediate area, $t$-test, $t_{70}=-6.41, P<0.05$; Eutrophic area, $t$-test, $\left.t_{70}=-7.21, P<0.05\right)$. The seagrass bed showed the most stable pattern over time.

Diversity as measured by the Shannon-Wiener index followed a pattern similar to evenness, with Simpson's D (dominance) showing the opposite, as expected (Fig. 5C,D). For the intermediate and eutrophic areas dominance tended to decrease over the 10-year period.

\subsubsection{PRC analysis}

For the pre-restoration period, PRC analysis revealed a clear spatial gradient over time related to eutrophication, where the declining Zostera noltii bed was closer to the 1993 Z. noltii reference, followed by the intermediate area and finally the eutrophic area (Fig. 6). In the post-restoration period, the seagrass bed and the intermediate area converged to the reference until the end of 2000 (Fig. 6). The effect of the intense floods on the macrofaunal community are clearly seen in the PRC analysis, with two tentative recovery periods
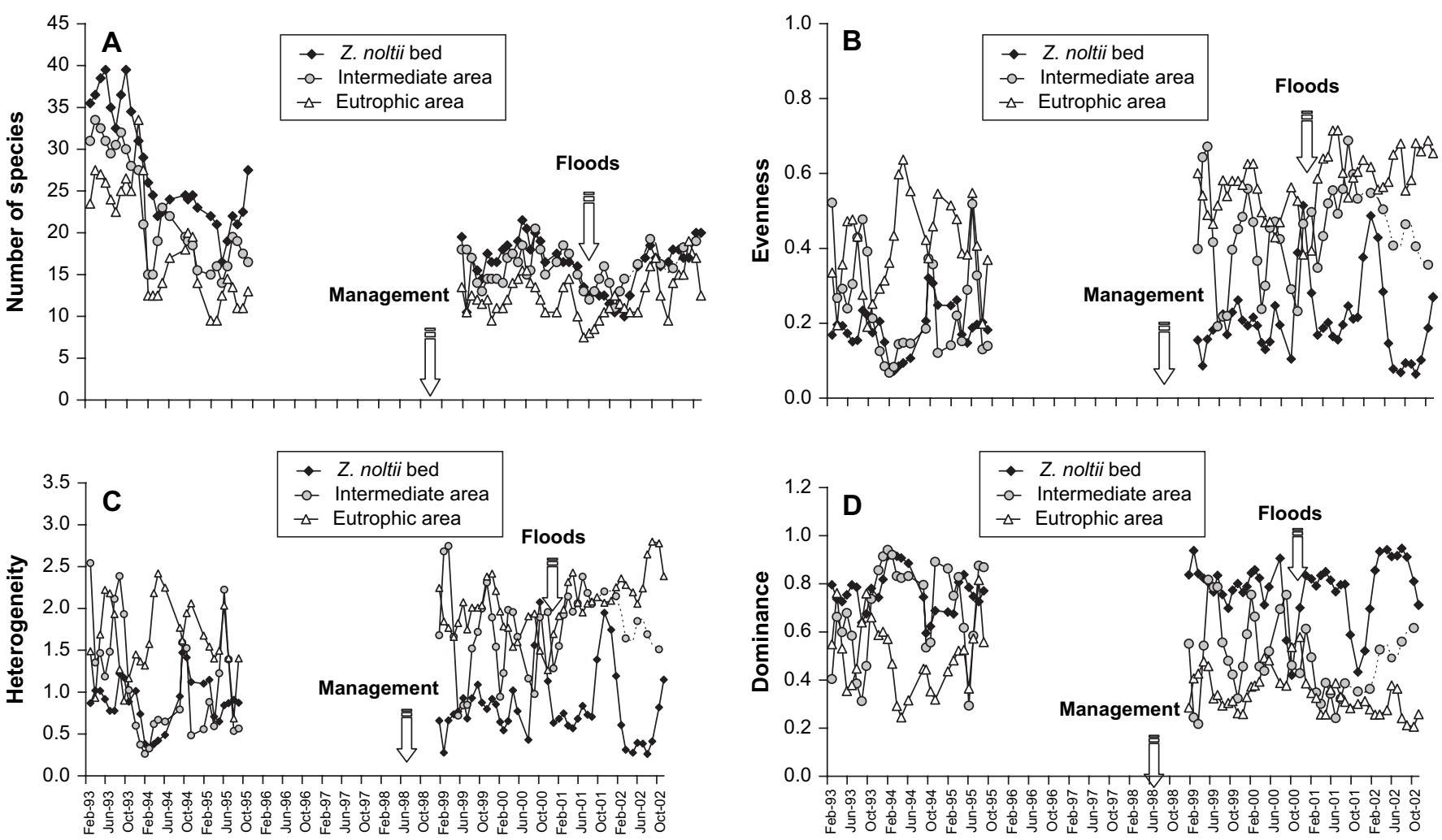

Fig. 5. Variation of the biological indices in the three sampling stations from 1993 to 2002. (A) Number of species; (B) evenness; (C) Shannon-Wiener index; and (D) Simpson index. 
Table 1

Total species richness for the three study areas and mean annual biomass for the entire estuary over a 10 -year period

\begin{tabular}{|c|c|c|c|c|c|c|}
\hline & $\begin{array}{c}\mathbf{N}^{\circ} \text { of } \\
\text { species }\end{array}$ & $\begin{array}{c}\mathbf{N}^{\circ} \text { of } \\
\text { species }\end{array}$ & $\begin{array}{c}\mathbf{N}^{\circ} \text { of } \\
\text { species }\end{array}$ & $\begin{array}{c}\text { Mean } \\
\text { Biomass } \\
\quad(\mathrm{g}\end{array}$ & \multirow{4}{*}{ Eutrophication } & \\
\hline 1993 & 36 & 30 & 27 & 38.7 & & \begin{tabular}{|c|} 
Macroalgal \\
Bloom
\end{tabular} \\
\hline 1994 & 24 & 18 & 15 & 37.9 & & \\
\hline 1995 & 22 & 17 & 12 & 46.6 & & Some algae \\
\hline 1999 & 16 & 16 & 12 & 32.9 & \multirow{3}{*}{ Recovery } & Management \\
\hline$\frac{2000}{2001}$ & $\begin{array}{l}18 \\
12\end{array}$ & 17 & 13 & $\begin{array}{l}43.5 \\
40.0\end{array}$ & & $\begin{array}{l}\text { Intense } \\
\text { floods }\end{array}$ \\
\hline 2002 & 18 & 18 & 15 & 56.3 & & Recovery \\
\hline
\end{tabular}

following the introduction of management measures, the first at the beginning of 2000 and the second in 2002 after the occurrence of the 2000/2001 floods.

In the PRC analysis, sampling date (time) accounted for $26.3 \%$ of the total variance within the data set, with $65.3 \%$ explained by the eutrophication gradient (time $\times$ site interaction) and only $8.4 \%$ of the total variance can be attributed to the differences between the sample replicates. Monte Carlo permutation tests revealed that the differences between the treatments and the control were statistically significant $(P<0.05)$ with the PRC diagram explaining $43.8 \%$ of the variance in treatment effects.

The taxa contributing most to these effects were the polychaete Chaetozone setosa and the oligochaete family Tubificidae. Both had high positive weights in the analysis, indicating a reduced abundance compared to the reference site. In contrast, the polychaete Alkmaria romijni had the highest negative weight (indicating an increase in abundance) (Fig. 6), consistent with the premise that small deposit-feeding polychaetes increase in eutrophic conditions (Pearson and Rosenberg, 1978).

\subsubsection{NM-MDS analysis}

The macrobenthic assemblages of the three study areas occupy different regions of the MDS plot, with the Zostera noltii samples separated from those in the eutrophic area by samples from the intermediate area (Fig. 7). Closer inspection reveals that the 1993 samples from the Z. noltii bed are separated from those of the subsequent years. The communities of the seagrass bed and intermediate area from 1999 to 2001 are closer than at the beginning of the study period, indicating a higher faunal similarity between them at this time. In addition, samples from the eutrophic area (2001) are quite isolated from the others, probably because the floods caused a strong impact on the community, specifically on suspension feeders. Samples from the intermediate and eutrophic areas showed the greatest scatter in the MDS plot, indicating more heterogeneity in time and space, perhaps reflecting less stability in those areas.
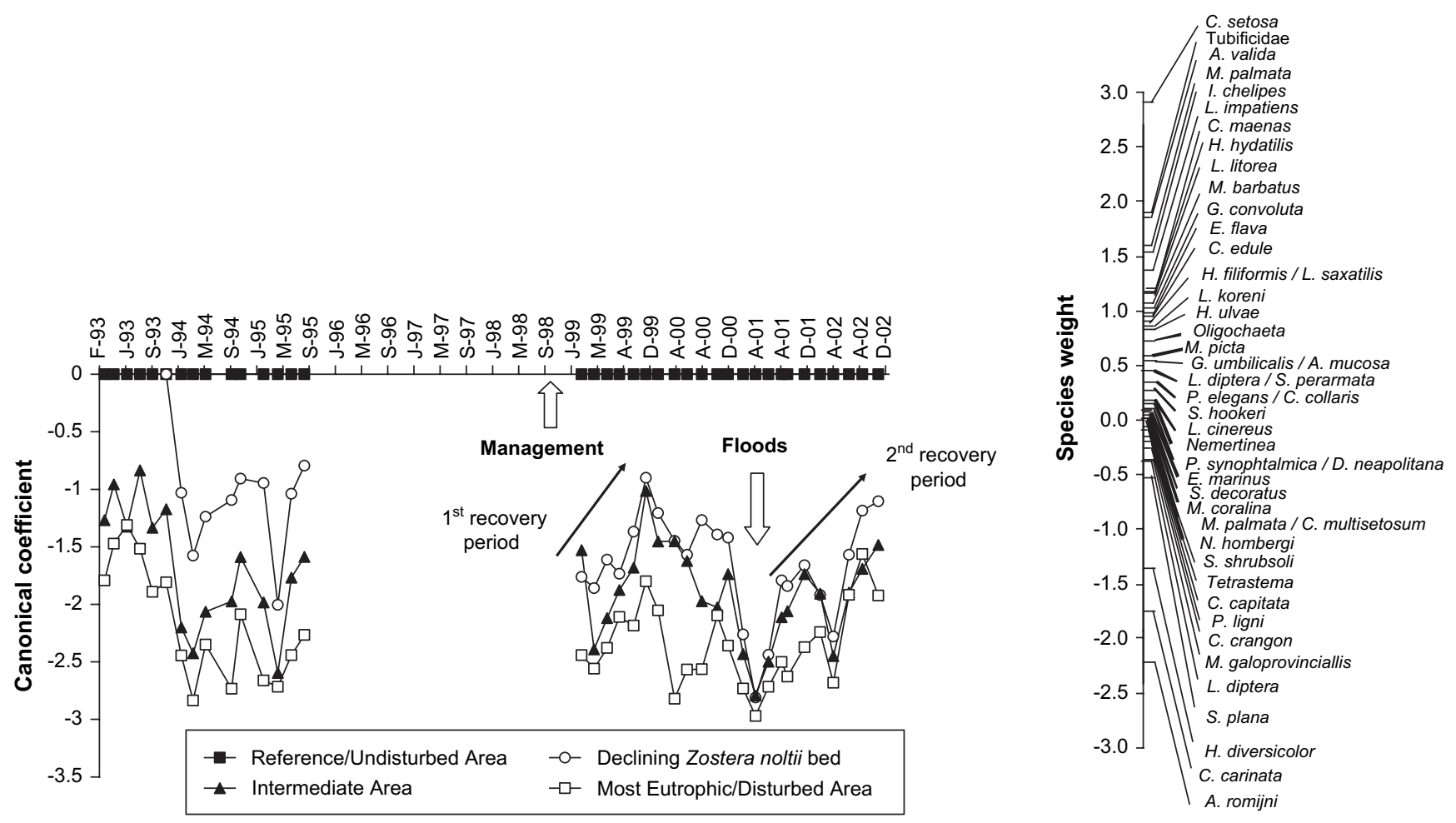

Fig. 6. Principal Response Curves (PRC) diagram showing the response of macrobenthic communities to different degrees of organic pollution/disturbance with species weights indicating the relative contribution of individuals' species to the community response. 


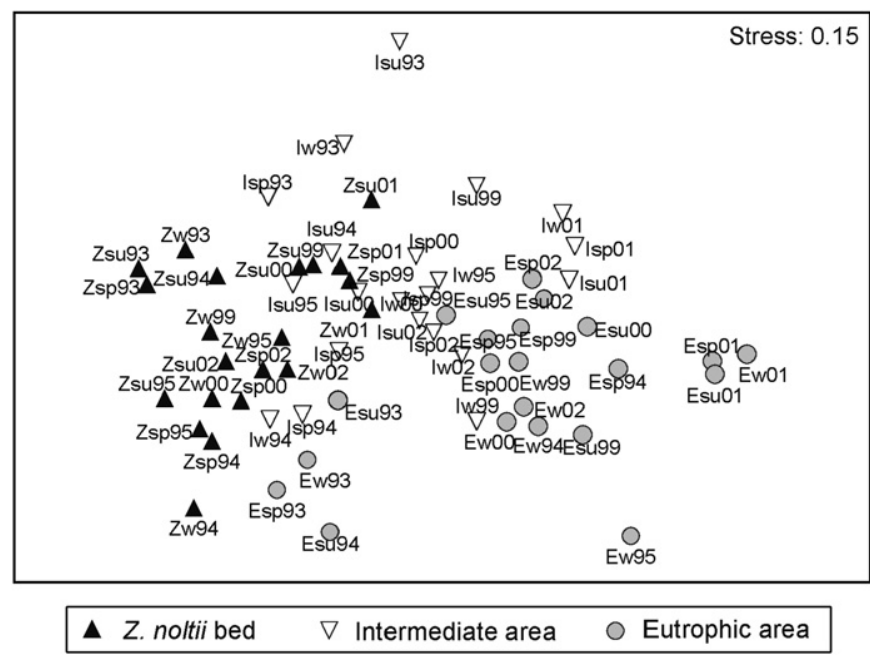

Fig. 7. Two-dimensional MDS ordination plot of macrobenthic communities. (Z) - Z. noltii beds; (I) - intermediate area; (E) - most eutrophic area; (w) winter; (sp) - spring; (su) - summer.

Significant differences between the three study sites were explored by ANOSIM. The Zostera noltii bed samples were significantly different from those in the intermediate area $(R=0.332, P=0.001)$ and from those in the eutrophic area ( $R=0.677, P=0.001)$.

\section{Discussion}

The environmental changes that occurred in the Mondego estuary during the last 20 years are reflected in the macrofaunal assemblages of the estuary which showed signs of recovery after the implementation of restoration measures. However, the recovery process after the management was not linear. The compounding (interacting) effect of the 2 major stressors (eutrophication and flooding) seems to have had a significant negative impact on the recovery ability (resilience) of the macrofauna. On the basis of the analyses reported here, we postulate that the loss of species and reduced performance of individuals following the first stressor (eutrophication) may have contributed to a decline of resilience of the macrobenthic assemblages to a second stressor (flooding), thereby slowing the recovery process. As the interactions between multiple stressors and the severity of the individual stressors may increase in the future due to climate change, marine systems are likely to become increasingly less resilient to their effects.

The temporal and spatial trends and patterns seen in these data are consistent with trends and patterns reported elsewhere (Savage et al., 2002). For example, over the period leading up to the introduction of the restoration plan, the assemblage in the area least affected by eutrophication, the seagrass bed, increased in biomass, coupled with an increase in opportunistic taxa, such as small deposit feeding polychaetes (mainly Alkmaria romijni and Capitella capitata) (see Cardoso et al., 2007 for more detail). In contrast, in the most eutrophic area, organic enrichment from algal blooms (in 1993 and 1995), led to a greater instability of the habitat and consequently to cyclical oscillations in biomass and density of the macrobenthic assemblages. During the post-restoration phase, recovery in biomass was greater than the recovery in density for all the three study sites, since there was an increase in longer-lived, large bodied taxa (e.g. Hediste diversicolor and Scrobicularia plana) which contributed significantly to biomass (Table 1). Furthermore, analysis of the macrobenthic assemblages revealed much less variation during this period due to the absence of algal blooms in the estuary since 1995 . However, the recovery phase was significantly affected by the extreme flooding events, slowing the system's return to its previous state. The macrobenthic assemblage at the eutrophic site appears less resilient than that in the seagrass bed, indicated by the longer return time to pre-flood event structure and composition (Fig. 3). The assemblage in the seagrass site also appears similarly less resilient to flood events following the earlier eutrophication period.

With respect to trophic groups, macroinvertebrate assemblages were dominated $(90 \%)$ by deposit-feeding species, indicative of the major role of detritus at the three sites. In addition, the seagrass bed supported a higher percentage of carnivores, herbivores and omnivores than the eutrophic area, which makes the latter less functionally rich. The 2000/2001 floods had a major impact on this community, especially on the subsurface-deposit feeders and suspension feeders (e.g. Scrobicularia plana and Cerastoderma edule), probably through the clogging of the feeding structures of these suspension feeders by the high turbidity (Norkko et al., 2002). Both these bivalves are economically important for the region, especially for the local fishermen who depend on estuarine resources directly. Furthermore, there is a suggestion of replacement of trophic groups (detritivores by omnivores) in the Zostera bed and intermediate area.

Comparing our study with other similar works in which was evaluated the effect of flood events on the macrobenthic communities (e.g. Norkko et al., 2002; Salen Picard and Arlhac, 2002; Salen Picard et al., 2003) we can conclude that different communities and habitats may respond differently to flooding events, depending on the ecology and feeding habits of the species. Some benthic communities may suffer deleterious effects due to catastrophic terrigenous clay deposition, which lead to anoxic conditions (Norkko et al., 2002) while other communities dominated by opportunistic species may be beneficiated with floods (Salen-Picard and Arlhac, 2002; Salen-Picard et al., 2003). The floods could act on the different components of the food web as pulses of organic matter leading to an increase of surface- and subsurfacedeposit feeders' assemblages.

In addition to changes in the relative abundance of individual taxa, consistent with patterns and trends seen elsewhere (Valiela, 1995), community-level attributes also responded to management. Following the decline in species richness during the eutrophication period (also observed in other systems: Lardicci et al., 2001; Hyland et al., 2005), the affected areas started to increase in diversity following the introduction of the management regime, mainly through changes in evenness and dominance (Fig. 5), and to a more limited extent in species 
richness. In comparison with the Orbetello lagoon, Tyrrhenian coast, Italy (Lardicci et al., 2001), the time scale of these responses were slower in the Mondego, and more similar to that observed in Alewife Cove, Connecticut, US, by Zajac and Whitlatch (2001). However, the latter study also revealed a decline in the abundance of organic enrichment indicator species (e.g. Capitella capitata) and an increase in species richness after implementation of the restoration programme. In the Mondego the response of the macrozoobenthic community was slower than at Alewife Cove, probably due to the combined effects of the multiple stressors described above. In summary, this study has shown that heavy flooding in the Mondego region during the process of recovery eutrophication had severe effects on these assemblages, effectively re-setting the recovery clock and slowing the overall return to the undisturbed state. This not only has implications for biodiversity conservation on the Mondego, but for the livelihoods of the people who depend on the estuary.

Thus, fish farms were directly affected due to the low salinities recorded over several consecutive months, which led to high fish mortality. Also, local fishermen that exploit the estuary mudflats directly were also affected because commercially important species such as Scrobicularia plana, Cerastoderma edule declined dramatically after the floods. Extreme weather events will become more frequent in the future and the ecosystems, and the goods and services they provide, risk never recovering fully if there resilience is been reduced by other stressors, such as pollution. Estuarine management needs to be more holistic and recognise the importance of such interactions between different stressors (Vinebrooke et al., 2004).

\section{Acknowledgements}

This work was supported by FCT (Fundação para a Ciência e Tecnologia) through a Post-Doc grant attributed to P.G. Cardoso (SFRH/BPD/22176/2005). The authors are indebted to all the colleagues that assisted in the field and lab work.

\section{References}

Adams, S.M., 2005. Assessing cause and effect of multiple stressors on marine systems. Marine Pollution Bulletin 51, 649-657.

Beukema, J.J., 1991. Changes in composition of bottom fauna of a tidal-flat area during a period of eutrophication. Marine Biology 111, 293-301.

Beukema, J.J., 1992. Long-term and recent changes in the benthic macrofauna living on tidal flats in the western part of the Wadden Sea. Netherlands Institute for Sea Research 20, 135-141.

Beukema, J.J., Flach, E.C., Dekker, R., Starink, M., 1999. A long-term study of the recovery of the macrozoobenthos on large defaunated plots on a tidal flat in the Wadden Sea. Journal of Sea Research 42, 235-254.

Cardoso, P.G., Lilleb $\varnothing$, A.I., Pardal, M.A., Ferreira, S.M., Marques, J.C., 2002. The effect of different primary producers on Hydrobia ulvae population dynamics: a case study in a temperate intertidal estuary. Journal of Experimental Marine Biology and Ecology 277, 173-195.

Cardoso, P.G., Pardal, M.A., Lillebø, A.I., Ferreira, S.M., Marques, J.C., Raffaelli, D., 2004. Dynamic changes of seagrass assemblages under eutrophication and implications for recovery. Journal of Experimental Marine Biology and Ecology 302, 233-248.
Cardoso, P.G., Brandão, A., Pardal, M.A., Raffaelli, D., Marques, J.C., 2005. The resilience of Hydrobia ulvae populations to anthropogenic and natural disturbances. Marine Ecology Progress Series 289, 191-199.

Cardoso, P.G., Bankovic, M., Raffaelli, D., Pardal, M.A., 2007. Polychaete assemblages as indicators of habitat recovery in a temperate estuary under eutrophication. Estuarine, Coastal and Shelf Science 71, 301-308.

Clarke, K.R., Gorley, R.N., 2001. Primer v5: User Manual/Tutorial. Primer-E Ltd, Plymouth.

Clarke, K.R., Warwick, R.M., 2001. Change in Marine Communities. An Approach to Statistical Analysis and Interpretation, second ed. Primer-E Ltd, Plymouth.

Dolbeth, M., Cardoso, P.G., Ferreira, S.M., Verdelhos, T., Raffaelli, D., Pardal, M.A., 2007. Anthropogenic and natural disturbance effects on a macrobenthic estuarine community over a 10-year period. Marine Pollution Bulletin 54, 576-585.

Frampton, G., Van den Brink, P.J., Wratten, S.D., 2001. Diel activity patterns in an arable collembolan community. Applied Soil Ecology 17, 63-80.

Harley, C.D.G. et al., 2006. The impacts of climate change in coastal marine systems. Ecology Letters 9, 228-241.

Hays, G.C., Richardson, A.J., Robinson, C., 2005. Climate change and marine plankton. Trends in Ecology and Evolution 20 (6), 337-344.

Hyland, J., Balthis, L., Karakassis, I., Magni, P., Petrov, A., Shine, J., Vestergaard, O., Warwick, R., 2005. Organic carbon content of sediments as an indicator of stress in the marine benthos. Marine Ecology Progress Series 295, 91-103.

IPCC WGI, 2001. Climate change 2001: the scientific basis, contribution of working group I to the third assessment report of the Intergovernmental Panel on Climate Change (IPCC). In: Houghton, J.T., Ding, Y., Griggs, D.J., Noguer, M., van der Linden, P.J., Xiaosu, D. (Eds.). Cambridge University Press, UK, 944 p.

Krebs, C.J., 1999. Ecological Methodology, second ed. Addison-Welsey Educational Publishers, Inc., Menlo Park, CA, 624 p.

Lardicci, C., Como, S., Corti, S., Rossi, F., 2001. Changes and recovery of macrozoobenthic communities after restoration measures of the Orbetello Lagoon (Tyrrhenian coast, Italy). Aquatic Conservation: Marine Freshwater Ecosystems 11, 281-287.

Lillebø, A.I., Neto, J.M., Martins, I., Verdelhos, T., Leston, S., Cardoso, P.G., Ferreira, S.M., Marques, J.C., Pardal, M.A., 2005. Management of a shallow temperate estuary to control eutrophication: the effect of hydrodynamics on the system nutrient loading. Estuarine, Coastal and Shelf Science 65, 697-707.

Martins, I., Pardal, M.A., Lillebø, A.I., Flindt, M.R., Marques, J.C., 2001. Hydrodynamics as a major factor controlling the occurrence of green macroalgal blooms in a eutrophic estuary: a case study on the influence of precipitation and river management. Estuarine, Coastal and Shelf Science 52, 165-177.

Norkko, A. et al., 2002. Smothering of estuarine sandflats by terrigenous clay: the role of wind-wave disturbance and bioturbation in sitedependent macrofaunal recovery. Marine Ecology Progress Series 234, 23-41.

Pardal, M.A., Cardoso, P.G., Sousa, J.P., Marques, J.C., Raffaelli, D., 2004. Assessing environmental quality: a novel approach. Marine Ecology Progress Series 267, 1-8.

Paerl, H.W., 2006. Assessing and managing nutrient enhanced eutrophication in estuarine and coastal waters: interactive effects of human and climatic interactions. Ecological Engineering 26, 40-54.

Pearson, T.H., Rosenberg, R., 1978. Macrobenthic succession in relation to organic enrichment and pollution of the marine environment. Ocean Marine Biology Annual Review 16, 229-311.

Salen-Picard, C., Arlhac, D., 2002. Long-term changes in a Mediterranean benthic community relationships between the polychaete assemblages and hydrological variations of the Rhône River. Estuaries 25, 1121-1130.

Salen-Picard, C., Arlhac, D., Alliot, E., 2003. Responses of a Mediterranean soft bottom community to short-term (1993-1996) hydrological changes in the Rhone river. Marine Environmental Research 55, 409-427. 
Santos, F.D., Forbes, K., Moita, R., 2002. Climate Change in Portugal. Scenarios, Impacts and Adaptation Measures - SIAM Project. Gradiva Publishers, Lisbon, Portugal, $456 \mathrm{p}$.

Savage, C., Elmgren, R., Larsson, U., 2002. Effects of sewage-derived nutrients on an estuarine macrobenthic community. Marine Ecology Progress Series 243, 67-82.

Ter Braak, C.J.F., Similaeur, P., 1998. Canoco Reference Manual and User's Guide to Canoco for Windows. Software for Canonical Community Ordination (version 4). Centre for Biometry Wageningen, Netherlands.

Valiela, I., 1995. Development of structure in marine communities: colonization and succession. In: Valiela, I. (Ed.), Marine Ecological Processes, second ed. Springer-Verlag, New York, 686 p.
Van den Brink, P.J., Ter Braak, C.J.F., 1999. Principal Response Curves: analysis of time-dependent multivariate responses of biological community to stress. Environment Toxicology Chemistry 18, 138-148.

Verdelhos, T., Neto, J.M., Marques, J.C., Pardal, M.A., 2005. The effect of eutrophication abatement on the bivalve Scrobicularia plana. Estuarine, Coastal and Shelf Science 63, 261-268.

Vinebrooke, R.D., Cottingham, K.L., Norberg, J., Scheffer, M., Dodson, S.I., Maberly, S.C., Sommer, U., 2004. Impacts of multiple stressors on biodiversity and ecosystem functioning: the role of species co-tolerance. Oikos 104, 451-457.

Zajac, R.N., Whitlatch, R.B., 2001. Response of macrobenthic communities to restoration efforts in a New England Estuary. Estuaries 24, 167-183. 